\title{
Vocal sequential exchanges and intragroup spacing in the Northern Muriqui Brachyteles arachnoides hypoxanthus
}

\author{
FRANCISCO D.C. MENDES ${ }^{1}$ and CÉSAR ADES ${ }^{2}$ \\ ${ }^{1}$ Departamento de Psicologia e Instituto do Trópico Subúmido, Universidade Católica de Goiás \\ Av. Universitária 1440, Cx. Postal 86, 74605-010 Goiânia, GO, Brasil \\ ${ }^{2}$ Departamento de Psicologia Experimental, Universidade de São Paulo \\ Av. Prof. Mello Moraes 1721, 05508-010 São Paulo, SP, Brasil
}

Manuscript received on January 15, 2004; accepted for publication on February 5, 2004.

\begin{abstract}
Sequential exchanges of vocalizations (staccatos and neighs) emitted by Northern Muriquis Brachyteles arachnoides hypoxanthus were recorded at the Biological Station of Caratinga, Minas Gerais State, Brazil. Staccatos and neighs containing larger proportion of short elements were preferentially produced during short-range exchanges; neighs, produced by a larger number of participants, were typical of long-range exchanges. Staccatos emitted by animals feeding in a dispersed manner contained a larger proportion of tonal elements than those emitted by muriquis feeding in a cohesive manner. Sequential exchanges seem thus to be constituted by two inter-related subsystems of calls that aid muriquis to coordinate intragroup spacing, despite the poor visibility of the habitat.
\end{abstract}

Key words: animal communication, signal exchange, vocal sequences, intragroup spacing, Muriqui.

\section{INTRODUCTION}

The Northern Muriqui Brachyteles arachnoides hypoxanthus, hereafter simply called muriqui, is a neotropical monkey found exclusively in the Atlantic Forest region of Brazil (Hilton-Taylor and Rylands 2002). Members of social groups are frequently out of visual range of one another. The high degree of dispersion, and the habitat's dense vegetation, may have favored the evolution of complex vocal signals in this species (Nishimura et al. 1988, Mendes 1997).

Part of the species repertoire is a set of combinatory calls that are produced in a particular pattern of turn-taking, named sequential exchanges. In a sequential exchange, one individual vocalizes, and

Correspondence to: Francisco Mendes

E-mail: francisco@ucg.br different group members usually respond one at a time with a single call each, and with little or no temporal overlap between adjacent calls. Such sequences occur throughout the day, in many different contexts, and are among the most frequent vocal expressions of muriquis (Mendes 1995).

Sequential exchanges are composed of a variety of acoustic forms that can be qualitatively discriminated from other vocalizations of the species' repertoire. Strier $(1986,1999)$ distinguished vocalizations occurring in sequences as "short" and "long" neighs, and Nishimura et al. (1988) noted that neighs, whinnies and screams usually evoked responses from other individuals. These labels account for part of the acoustic repertoire present in sequential exchanges. Less conspicuous calls composed of short pulsed sounds are also fre- 


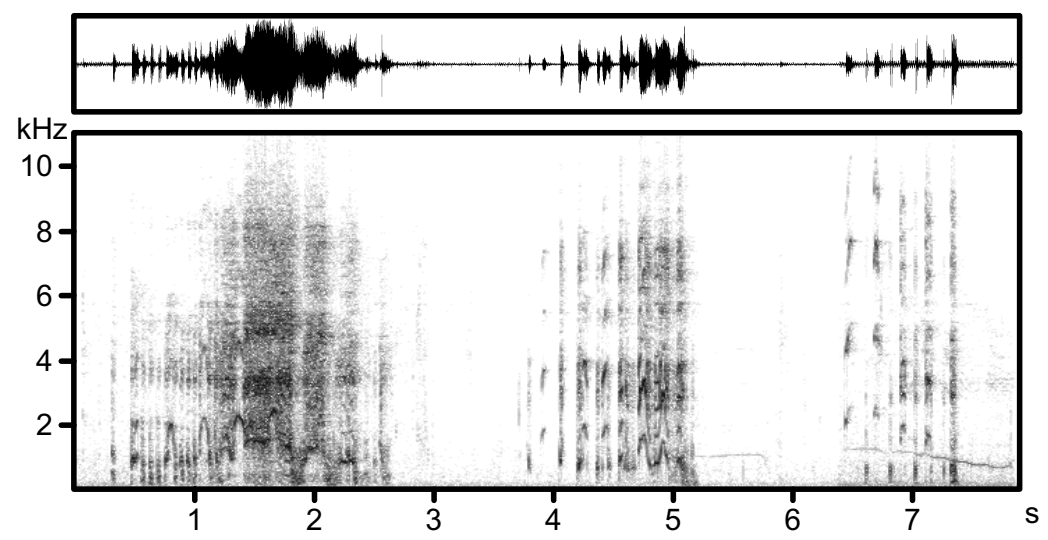

Fig. 1 - Three vocalizations during the same sequential exchange. Each vocalization is formed by a succession of elements emitted by a single individual. The exchange was composed of all three vocalizations, that were emitted without temporal overlap. Note also that the first two vocalizations are initiated by a sequence of short elements that are followed by long elements, and represent neighs. The third vocalization is a staccato, composed solely by short elements.

quently exchanged by group members. Longer and louder "run-on" "utterances are also used, in combination with pulsed sounds. Some combinations give a neigh-like or scream quality to the vocalization, but both pulsed and run-on sounds are combined in a variety of ways (Mendes 1995, Ades and Mendes 1997).

We will present and discuss results taken from a broader study (Mendes 1995) that indicate a relationship between sequential exchanges and the coordination of intragroup spacing.

\section{MATERIALS AND METHODS}

Data were collected at the Estação Biológica de Caratinga (see Strier 1999). The study group was composed of 8 adult and 2 subadult males, 12 adult and 5 subadult females, and 16 immature members. Spontaneous calls of adult individuals $(n=322)$ were recorded from September to November of 1990, with a Marantz PMD430 cassette recorder and a Sennheiser ME-88 directional microphone. Acoustic analyses were conducted with RTS/Signal version 3.1 (Beeman 1989).

Calls within exchanges showed considerable acoustic variability and were formed by the combination of recurring elements (Mendes 1995, Mendes and Ades, in prep.). In this paper, analyses will focus on two distinctions (Fig. 1): a) short elements (less than $100 \mathrm{~ms}$ in duration) and long elements; b) staccatos (calls composed only of short elements; $\mathrm{n}=202$ ), and neighs (at least one long element in their composition; $\mathrm{n}=120$ ).

Data on the context of emission included: 1) the total number of calls in the exchange (an exchange was considered to be finished after a 10 second period of silence); 2) the maximum distance of other participants in relation to the recorded caller ( 0 to $20 \mathrm{~m}, 20$ to $50 \mathrm{~m}, 50$ to $100 \mathrm{~m}$, more than $100 \mathrm{me}-$ ters); 3) the presence of potential referents (large feeding tree, potential predators, members of other social groups, sexual receptivity of female callers).

\section{RESULTS}

\section{SHORT AND LONG-RANGe ExCHANGES}

Sequential exchanges varied both in the number of participants (callers) and in the degree of dispersion among them. Sixty of the 322 calls were not answered by other individuals. The mean number of 
calls in an exchange was $4(\mathrm{sd}=3.4$; median $=3$; maximum $=31$ ). Participants of the same exchange were sometimes within visual range of one another and sometimes more than $400 \mathrm{~m}$ apart.

A one way analysis of variance showed a significant positive relationship between the total number of calls in an exchange and the maximum distance of participants in relation to the focal caller $\left(F_{(3,239)}=33.12 ; p<0.00005 ;\right.$ Fig. 2). Sequential exchanges were associated with both interactions between a few nearby individuals (short-range vocal exchanges) and interactions of larger numbers of individuals spread out over larger areas (long-range exchanges).

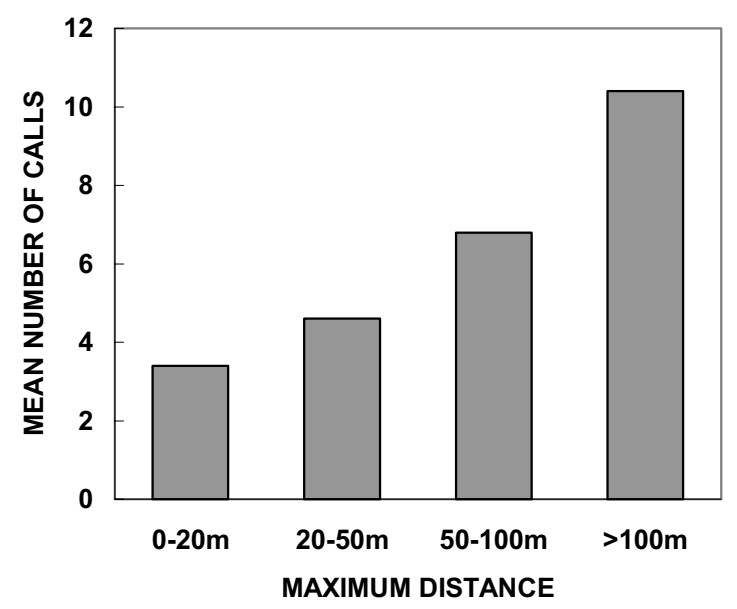

Fig. 2 - Mean number of calls in exchanges occuring at different classes of maximum distance of participants relatively to the focal caller.

Staccatos were mainly produced during shortrange exchanges; neighs, particularly those with none or few short elements, were mainly produced during long-range exchanges $\left(\chi^{2}=19.87 ; \mathrm{df}=3\right.$; $\mathrm{p}<0.001)$. This relationship appeared clearly when the total number of short and long elements was counted for calls across the four groups of maximum distance (Fig. 3). As the distance increased, so did the proportion of long elements $\left(\mathrm{F}_{(2,239)}=2.14\right.$; $\mathrm{p}<0.05)$.

\section{TONAL AND Harsh Staccatos}

Short elements occurring in staccatos were ordered into 5 types, according to the increasing degree of harshness (tri, t, h, r, p). The percentage of short elements of each type was calculated for staccatos which occurred in one of two feeding contexts: in the "clustered" context, all muriquis fed at the same tree; in the "dispersed" context, individuals fed at different trees. The distribution of short element types between contexts was not random $\left(\chi^{2}=84.26\right.$; $\mathrm{df}=4 ; \mathrm{p}<0.001)$. Short elements of intermediate harshness occurred in equal proportions in both contexts. Tonal short elements were relatively more frequent in the dispersed context; harsh short elements were relatively more frequent in the clustered context (Fig. 4).

\section{Specific Patterns of Neighs}

Three patterns of neighs were almost exclusively emitted by receptive females: neighs formed by long tonal emissions alone, neighs formed by the succession of a modulated element with harsh overtones, and neighs that included 'trill-sounding', successions of rapid pulses. Another vocal pattern, associated with periods of great group dispersion during group encounters, was formed by a succession of elements that started with a tonal emission and ended with a sudden frequency drop that blended into a harsh, low pitch emission.

\section{DISCUSSION}

Sequential exchanges seem to be constituted by two inter-related subsystems of calls that aid muriquis to coordinate activities, despite dispersion of group members and poor visibility in the habitat. Staccatos and neighs containing a large proportion of short elements are preferentially used in the coordination of nearby individuals. Since the occurrence of a great group cohesion is relatively rare, such calls are most frequently used in exchanges containing a relatively low number of participants.

Staccatos may also obey motivational-structural rules (Morton 1982), and work as a mecha- 


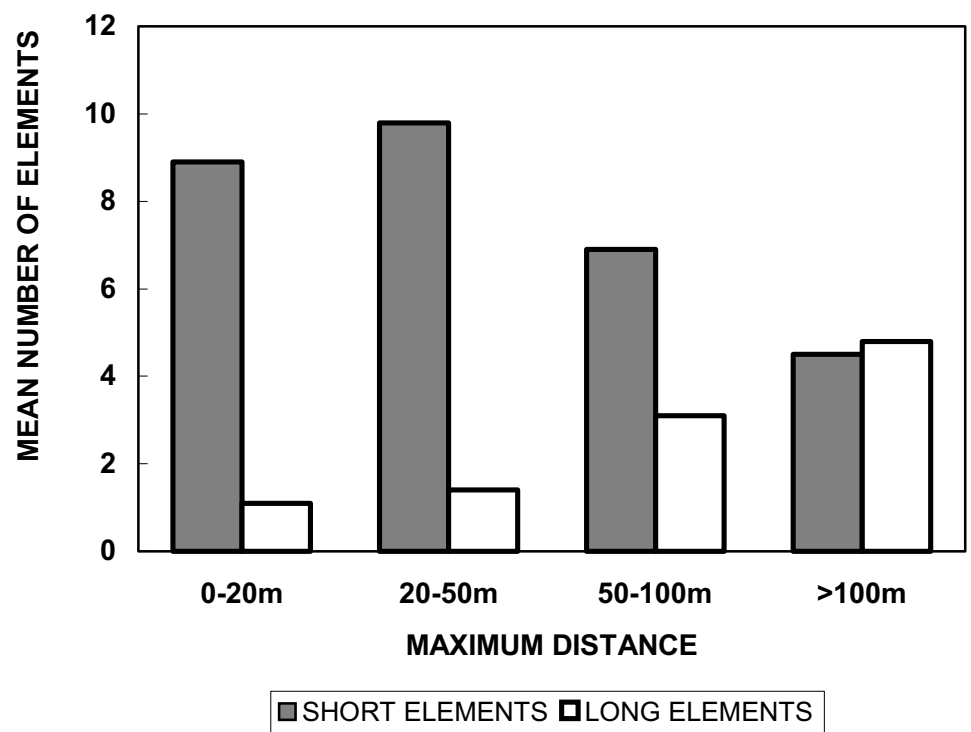

Fig. 3 - Mean number of short and long elements in calls performed at the four classes of maximum distance of participants relative to the focal caller.

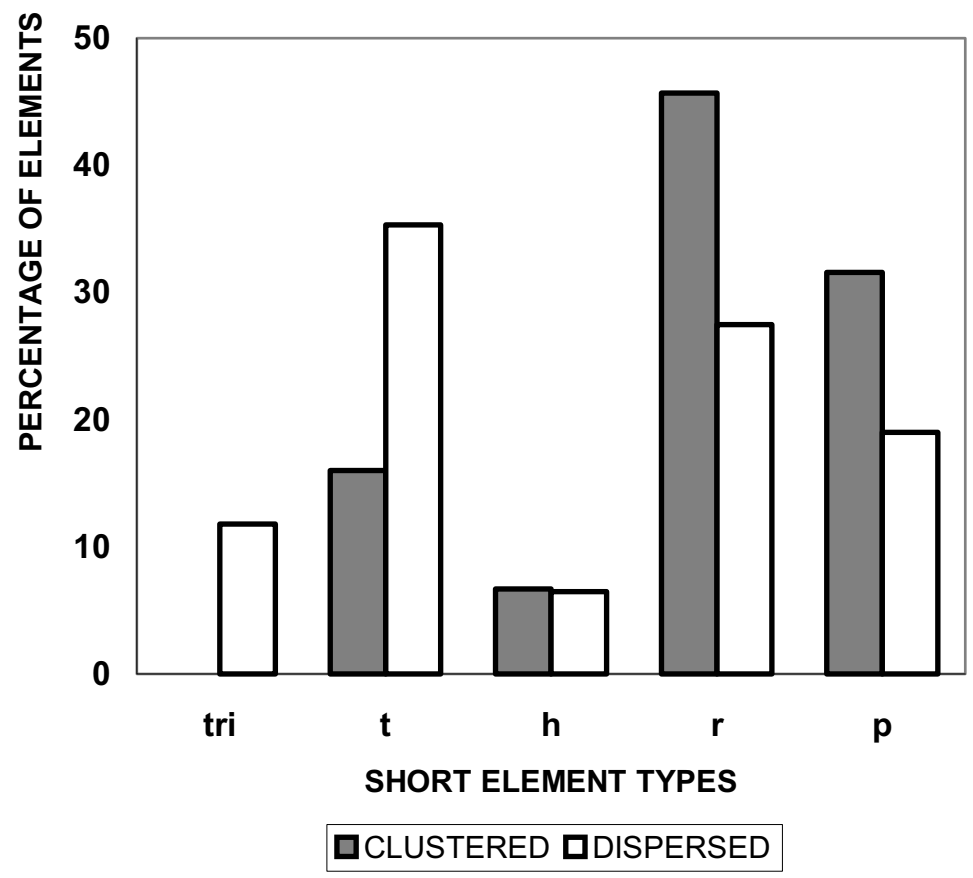

Fig. 4 - Percentage of short elements types (p, t, h, r, tri) recorded in two feeding contexts: muriquis feeding on the same tree (clustered), or in different trees (dispersed). 
nism for competition avoidance. In some primates, the degree of harshness and pitch of calls relates to tendencies of spatial proximity or spatial dispersion (Robinson 1982, Boinski 1991). In short-range exchanges of muriquis, different forms of short elements could be emitted according to the availability of resources, and/or tendencies of spatial proximity. Calls dominated by harsh elements, for example, could represent a potential conflict, and result in the maintenance or increase of distances among nearby listeners. Calls dominated by higher and more tonal elements, on the other hand, were more often produced by dispersed individuals, or individuals at sites with abundant food. The relative frequency of emission of short elements in "single source" and "feeding" contexts seems to support this hypothesis.

When the group is dispersed, muriquis may communicate with nearby individuals through staccatos, or emit neighs dominated by long elements, which reach a larger number of group members. In this way, exchanges containing neighs, especially those with relatively small numbers of short elements, present on average larger number of participants.

The specificity of referents in short and longrange neigh production is also relevant. Short-range interactions may be accompanied by redundant visual cues. Callers and receivers of long-range vocalizations may, on the other hand, benefit by more specific information, such as the sexual receptivity of female callers, and on the proximity of neighbor groups.

Variables related to the spatial distribution of individuals are important determinants of vocal production in primates' intragroup vocalizations (Snowdon and Hodun 1981, Robinson 1982, Boinski and Mitchell 1992, Palombit 1992, Boinski 1996, Rendall et al. 1999). Exchange calls are, in most species, used at relatively short distances. The sequential exchanges of muriquis are remarkable for their great variability in distances between participants. Some calls are restricted to nearby individuals (i.e. muriquis at a 50 meters range), while oth- ers include participants dispersed over larger areas. A single exchange may include both short-range and long-range calls of different acoustic properties. This flexibility in structure and usage indicates the possibility of differences in the function and information content of calls, a possibility that deserves further attention.

\section{ACKNOWLEDGMENTS}

The research counted with the collaboration of Charles T. Snowdon and Karen B. Strier, funds from National Geographic Society (CTS and KBS), CNPq, N.S.F. (KBS), FAPESP, C.I.-Brazil, and logistic support from Fundação Biodiversitas.

\section{RESUMO}

Intercâmbios seqüenciais de vocalizações (estacados e relinchos) emitidos por Muriquis-do-norte Brachyteles arachnoides hypoxanthus foram registrados na Estação Biológica de Caratinga, em Minas Gerais. Os estacados e os relinchos compostos de grande número de elementos curtos eram principalmente emitidos nos intercâmbios a curta distância; os relinchos, produzidos por um maior número de participantes, eram típicos dos intercâmbios a longa distância. Os estacados de animais que se alimentavam de modo disperso continham maior proporção de elementos tonais do que os emitidos por muriquis que se mantinham agrupados durante a alimentação. Os intercâmbios seqüenciais parecem, assim, constituídos de dois subsistemas de chamados através dos quais os muriquis conseguem coordenar o espaçamento intragrupal, apesar da baixa visibilidade do ambiente.

Palavras-chave: comunicação animal, intercâmbio de sinais, seqüências vocais, espaçamento intragrupal, muriqui.

\section{REFERENCES}

Ades C And Mendes FDC. 1997. Uma aproximação etológica às vocalizações do muriqui. Temas em Psicologia 3: 135-149.

Beeman K. 1989. “'Signal', User's Guide. Belmont: Engineering Design.

BoINSKI S. 1991. The coordination of spatial position: a field study of the vocal behaviour of adult female squirrel monkeys. Anim Behav 41: 89-102. 
BoINSKI S. 1996. Vocal coordination of troop movement in squirrel monkeys (Saimiri oerstedi and S. sciureus) and white-faced capuchins (Cebus capucinus). In: NorCONK MA ET AL. (Eds), Adaptive radiation of neotropical primates. New York: Plenum Press, p. 251-269.

Boinski S AND Mitchell CL. 1992. Ecological and social factors affecting the vocal behaviour of adult female squirrel monkeys. Ethology 92: 316-330.

Hilton-Taylor C And Rylands AB. 2002. The 2002 IUCN Red List of Threatened Species. Neotrop Primates 10: 149-153.

Mendes FDC. 1995. Interações vocais do muriqui. PhD Thesis. Universidade de São Paulo, 134 p.

Mendes FDC. 1997. Padrões de interação vocal do muriqui. In: FERrari SF. (Ed), A Primatologia no Brasil, V. Belém, PA: Sociedade Brasileira de Primatologia, p. 94-118.

Morton ES. 1982. Grading, discreteness, redundancy, and motivational-structural rules. In: KRoODSMA DE AND Miller EH. (Ed), Acoustic communication in birds, vol 1. New York: Academic Press, p. 183-212.

Nishimura A, Fonseca GAB, Young AL, Strier KB, Mittermeier RA and Valle CMC. 1988. The Muriqui, genus Brachyteles. In: MitTermeier RA ET AL. (Eds), Ecology and Behavior of Neotropical Primates, vol. 2. Belo Horizonte, MG: World Wildlife Fund and Sociedade Brasileira de Primatologia, p. 577-599.
PALOMBIT RA. 1992. A preliminary study of vocal communication in wild long-tailed macaques (Macaca fascicularis). II. Potential of calls to regulate intragroup spacing. Int J Primatol 13: 183-207.

Rendall D, Seyfarth RM, Cheney DK and OWren MJ. 1999. The meaning and function of grunt variants in baboons. Anim Behav 57: 583-592.

RobINSON JG. 1982. Vocal systems regulating withingroup spacing. In: SNOwdon CT ET AL. (Eds), Primate Communication. Cambridge, MA: Cambridge University Press, p. 94-116.

SnOwdon CT and Hodun A. 1981. Acoustic adaptations in pygmy marmoset contact calls: locational cues vary with distance between conspecifics. Behav Ecol Sociobiol 9: 295-300.

STRIER KB. 1986. The behavior and ecology of the Wooly Spider Monkey, or Muriqui (Brachyteles arachnoides E. Geoffroy 1806). Ph.D Thesis. Cambridge, MA: University of Harvard, $220 \mathrm{p}$.

STRIER KB. 1999. Faces in the Forest: the endangered Muriqui monkeys of Brazil, $2^{\text {nd }}$ edition. Boston, MA: Harvard University Press, 160 p. 